\title{
Демидько Е.В. \\ О цели профессиональной подготовки кадров: познание или знание
}

ФБГОУ ВО «Тихоокеанский государственный университет»

(Россия, Хабаровск)

doi: 10.18411/trnio-01-2022-135

\section{Аннотация}

Статья посвящена актуальной сегодня проблеме конкретизации целевых функций системы профессиональной подготовки кадров: дать необходимые для профессиональной деятельности знания или обучить методологии познания объективных закономерностей профессиональной сферы деятельности. Автор подчеркивает, что без такой конкретизации невозможно сформировать как соответствующие функции структуру, содержание и технологию учебного процесса, так и определить адекватные для каждого из направлений обучающихся требования.

Ключевые слова: система профессионального образования, функции системы образования, подготовка кадров, познание, знание.

\section{Abstract}

The article is devoted to the actual problem of concretization of the target functions of the system of professional training of personnel: to give the knowledge necessary for professional activity or to teach the methodology of cognition of objective laws of the professional sphere of activity. The author emphasizes that without such concretization it is impossible to form both the appropriate functions of the structure, content and technology of the educational process, and to determine adequate requirements for each of the directions of students.

Keywords: professional education system, functions of the education system, personnel training, cognition, knowledge, cognition.

Система профессионального образования выполняет несколько целевых функций. Основная из них часто определяется как «подготовка квалифицированного работника соответствующего уровня и профиля, конкурентоспособного на рынке труда, компетентного, ответственного, свободно владеющего своей профессией и ориентированного в смежных областях деятельности, способного к эффективной работе по специальности на уровне мировых стандартов, готового к постоянному профессиональному росту, социальной и профессиональной мобильности; удовлетворение потребностей личности в получении соответствующего образования» [1]. За такой многозначностью пропадает и размывается понимание места и роли профессионального образования в системе институтов государства, в структуре народно-хозяйственного комплекса страны, что затрудняет определение четких и достижимых задач, которые, тем не менее, объективно существуют. Для того, чтобы прояснить указанную многозначность необходимо рассмотреть систему профессиональной подготовки в аспекте ее соотношения с практикой функционирования производственноэкономической структуры соответствующей отрасли, что и является целью данной статьи.

Основными методами исследования явились: содержательный анализ различных работ, необходимых для рассмотрения проблематики данной статьи; структурный и системный анализ соответствия внешних, как для организаций профессиональной подготовки, так и для отраслей, условий и факторов, определяющих принципы функционирования этих организаций.

Рассмотрим типовую иерархическую структуру производственно-технической системы отрасли и систему профессиональной подготовки как единое целое (см. рис. 1). 


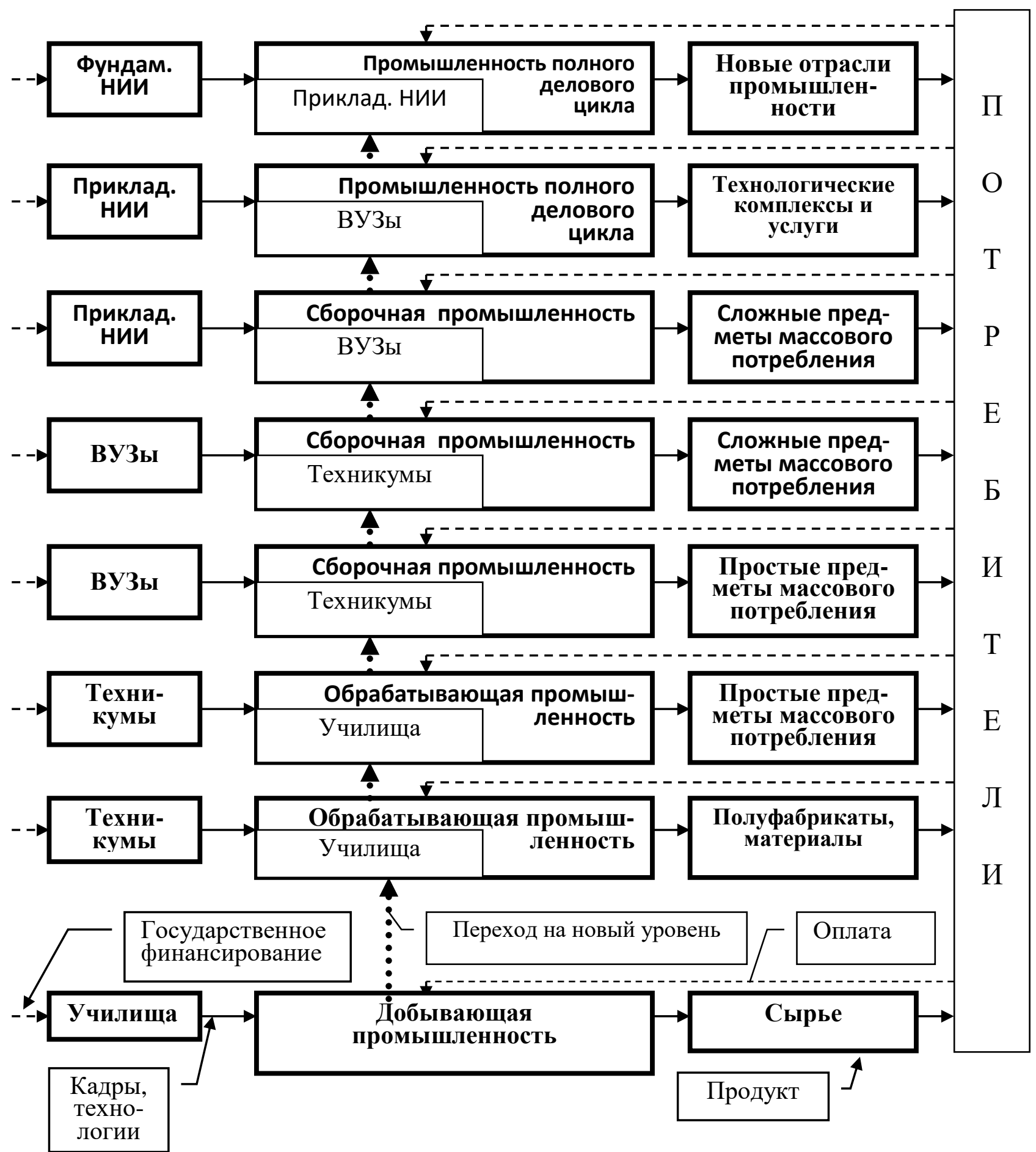

Рисунок 1. Структура производственно-технической системь

Из приведенной схемы можно сделать вывод, что есть две основных целевых функции по уровням профессиональной подготовки кадров.

1. Глобальная - обеспечение кадрами для создания и роста научнотехнического потенциала страны. Главная задача здесь - это научить методологии познания закономерностей в сфере профессиональной деятельности.

2. Локальная - обеспечение потребностей региона в профессиональных кадрах. Здесь основная задача - дать необходимые для профессиональной деятельности знания.

На методологическом уровне это можно определить как дилемму «знание или познание», другими словами, что является превалирующим в профессиональной подготовке: или дать необходимые для профессиональной деятельности знания, или обучить 
методологии познания объективных закономерностей профессиональной сферы деятельности. При этом под познанием будем иметь в виду процесс деятельности, основной целью которого является выявление и знаковое отражение законов объективной реальности в сознании человека; под знанием - совокупность знаковых систем, отражающих объективные связи всех аспектов жизни человечества (природные, социальные и другие законы и закономерности).

О познании следует сказать: обучение методологии познания закономерностей разнообразных явлений объективно представляет из себя значительно более сложную задачу, чем обучение необходимым для профессиональной деятельности знаниям. Это обусловлено тем, что научение знаниям требует лишь строго структурированное и иерархизированное знание, которое будет являться моделью будущих знаний обучающегося, с последующим развитием навыков их применения в практической профессиональной деятельности. Этот метод подходит для подготовки большинства будущих специалистов. Что же касается обучения методологии познания, то: во-первых, этим могут овладеть только специалисты уже имеющие определенный фундамент теоретических знаний и практических умений, причем часто в нескольких смежных отраслях знаний; во-вторых, здесь необходим исследовательский и творческий склад ума; в-третьих, что не менее важно, соответствующая внутренняя мотивация и явно осознанное желание узнать непознанное.

В качестве аргументации вышесказанного рассмотрим социальный объект и его характеристики.

Социальный объект - эмпирический объект (человек или группа людей), который периодически совершает совокупность действий, самовоспроизводящий основные черты, определяющие сущность этого объекта [2]. Экспликацию социального объекта можно представить в виде схемы самого объекта и социальных его характеристик, которые определяются в процессе взаимодействия (см. рис. 2).

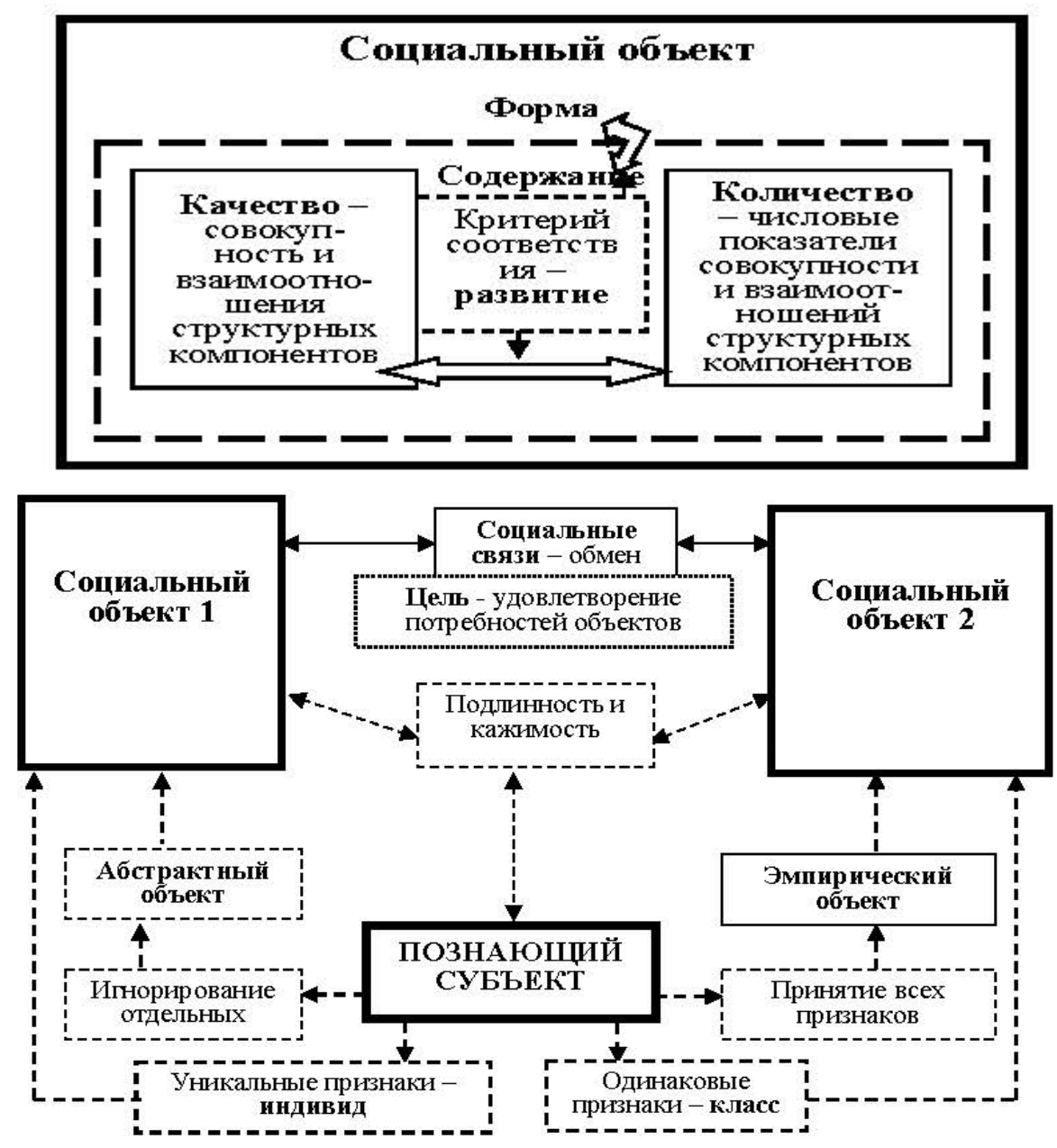

Рисунок 2. Социальный объект и его характеристики [3] 
В данном случае это готовые знания, которые решают прикладную целевую функцию и требуются в тех сферах, где большой объем трудовой деятельности связан с общением: педагогика, социология, психология, руководство персоналом, торговля, реклама... Эти знания должны включаться в перечень обязательных для изучения по соответствующим направлениям подготовки кадров. Однако, чтобы в данной сфере получить новые знания, необходимо знать и учитывать современные тенденции в области цифровых технологий, связанных с искусственным интеллектом, социальными сетями, системами коммуникаций, современными инструментальными и психофизиологическими методами воздействия на сознание социального субъекта и т.д. Это уже новые методы и инструменты анализа, другие подходы к подготовке кадров в данной области, которые только и могут обеспечить возможности перехода здесь от локальной целевой функции к глобальной.

Таким образом, очевидно, что исходя из уровня целей должен определяться подход к структуре, содержанию и технологиям учебного процесса. Немаловажное значение имеет также отбор кадров для обучения, так как это уже было отмечено ранее, не каждый способен к восприятию и пониманию методологии познания.

$$
* * *
$$

1. Дралюк, И. А. Повышение качества подготовки специалиста как условие его конкурентоспособности / И. А. Дралюк, Р. С. Дралюк. - Текст : непосредственный // Теория и практика образования в современном мире : материалы VI Междунар. науч. конф. (г. Санкт-Петербург, декабрь 2014 г.). - Санкт-Петербург : Заневская площадь, 2014. — C. 297-300. — URL: https://moluch.ru/conf/ped/archive/145/6541/ (дата обращения: 07.01.2021).

2. Зиновьев А. А. На пути к сверхобществу / А. А. Зиновьев. - М.: Центрполиграф, 2000. - 638 с.

3. Демидько, Е.В. Социология общества в рисунках и таблицах (на основе книги А.А. Зиновьева «На пути к сверхобществу»): монография / Е.В. Демидько. - Хабаровск : Изд-во Дальневосточ. гос. гуманитар. ун-та, 2013. -44 c.

\title{
Дьяченко Е.С. ${ }^{1}$, Кадеева О.Е. ${ }^{2}$, Сырицына В.Н. ${ }^{2}$ \\ Интерактивный плакат как средство обучения на уроках информатики
}

\begin{abstract}
${ }^{1}$ Школа педагогики Дальневосточного федерального университета
${ }^{2}$ Департамент теории и практики преподавания математики, информатики и естественных наук Школы педагогики Дальневосточного федерального университета
\end{abstract} (Россия, Уссурийск)

doi: 10.18411/trnio-01-2022-136

\section{Аннотация}

В данной статье рассматриваются вопросы эффективности применения цифровых интерактивных плакатов для вовлечения учащихся в процесс обучения. Авторы также рассматривают различные ресурсы для создания интерактивных плакатов и их использование в условиях очной и дистанционной формы обучения.

Ключевые слова: интерактивный плакат, цифровой интерактивный плакат, средство обучения, дидактический материал.

\section{Abstract}

This article discusses the effectiveness of using digital interactive posters to engage students in the learning process. The authors also consider various resources for creating interactive posters and their use in full-time and distance learning.

Keywords: interactive poster, digital interactive poster, learning tool, didactic material.

К современной школе с каждым годом предъявляют всё больше и больше требований, поэтому необходимо вносить новые подходы к организации обучения, которые бы опирались на быстро развивающиеся информационные технологии. Также в настоящее время необходимо обучать детей умению мыслить, самостоятельно добывать информацию и 